\title{
Determinants of regional agroindustry and spillovers between Siberian local markets
}

\author{
Tatyana Krasnova ${ }^{1}$, Shahid Nawaz Khan², Alexander Pozdnyakov ${ }^{1}$, and Alexander \\ Vilgelm ${ }^{1, *}$ \\ ${ }^{1}$ Khakas State University N.F. Katanova, Abakan, Russia \\ ${ }^{2}$ National University of Sciences and Technology, Islamabad, Pakistan
}

\begin{abstract}
This paper investigates the relationship between spatial distribution of economic activity and local markets of primary sector in panel of Siberian regions over the period 2005-2018, using measure of localization that is Theil index considering two hierarchical levels. Section 2 describes the data and method using geospatial toolset that we have proposed, discusses the construction model for study spatial concentration spillovers between local markets. In Section 3 we study how the processes of urbanization and growth of population density in cities and agricultural development in rural areas affect the formation of local housing markets, and as a consequence, the associated local markets for goods and resources; and the last section concludes. Keywords: economic growth, regional economics, agricultural industry, local markets, spillovers, housing market
\end{abstract}

\section{Introduction and theoretical basis}

Within current regional economic conditions availability of external markets has positive effects in the form of specialization, growth of efficiency and competition and spillovers in the form of deepening urbanization processes, regional divergence, reduction of diversification and increase of localization, high clustering, leading to the formation of single-industry towns (especially mining single-industry towns), decrease in population density and monopolization. Labor-migration flows as a result of increased dynamics spillover to the local housing market, which has a major impact on the social sphere.

Many of the processes taking place in terms of urbanization entail structural transformations in those agglomerations most affected by competition between industries and local markets for goods and resources [1-3]. As a result of localization and further evolution, spatial new formations are formed, which can be described by the characteristics of urban-ecosystems. An example can be single-industry towns, where diversification cannot reduce the main role of industry, which has the largest weight in the gross domestic product. GDP per capita may not change over time due to labor-migration flows, so this indicator is important for characterizing diversification processes in the context of spatial distribution. It is especially relevant for macroregions of developing countries.

\footnotetext{
* Corresponding author: asvilhelm@gmail.com
} 
The strategy of technological modernization of the macroregion's industrial sector depends directly on the extent to which infrastructure industries ensure the availability of technological and logistical supply chains to create added value in the industry. It is also necessary to take into account the multi-service function of the urban ecosystem to maintain the necessary processes of migration movements between points of growth and points of urbanization for spatial connectivity. Government support to development of macroregions in emerging economies may enable local markets to overcome their infrastructural facility constraints and succeed in expanding their operations in context spatial distribution of economic activity. On this basis, it is important to develop the main criteria aspects of the methodology of choosing the forms and methods of providing government support to helps to increase economic activity area in the context of investing in infrastructure, attracting new labor, developing the social sphere, etc. Thus, the theoretical attitude is formed that the development of macroregional potential is promoted by the potential of urban-ecosystems, the main indicator of which is the formation and functioning of local housing markets.

This article studies local products and resources markets of primary sector in macroregion, the sectoral structure of which includes the building materials (i.e. mining) industry and the agriculture industrial complex, including agricultural production, processing and services connected with related (service) production links. Production activities are to be investigated with a focus on the change in efficiency associated with secondary effects. We investigate how the inclusion of a municipal level dataset, which is considered important to study in regional large-scale systems, and new in current research, can make the resulting numerical model socio-economic monitor with improved explanatory power.

\section{Data and method}

This study examines the forces driving distribution of economic activity and spillovers of local emerging-markets of goods and resources. In this regard, the development of tools that proposes a new conceptual basis for monitoring, based on modeling regional processes under the influence of determinants of regional agroindustry and spillovers between Siberian local markets. Proposed model is based on the assertion proved by Williamson [4] about the relationship between regional development and spatial inequality.

We focus on the spatial distribution of production activity within 10 Siberian regions (included 3977 municipalities) to perform assessment of economic dynamics in industrial clusters of primary sector of macroregion. The hierarchical structure of the model consists in gradual transition of Theil index calculation [5] which measures the degree of discrepancy between the spatial structure of economic activity of local market entities. The minimum index value there is a complete coincidence of the spatial distribution of population density as a measure of scale local markets and the spatial concentration of economic activity as measuring efficiency. Maximum value of this index is an indicator of a high concentration degree, corresponding to the maximum possible market size within the localized area. If there is a positive or negative trend in dynamics, this may indicate an increase in the localization or distribution of economic activity within regions. For the measure regional level this index is calculated as follows:

$$
T^{t}=\frac{1}{10} \sum_{i=1}^{10} \frac{x_{i}}{x} \ln \left(\frac{x_{i}}{x}\right)=\sum_{i=1}^{10} g_{i, t} \ln \left(10 g_{i, t}\right)
$$

where $i$ indexes regions, $x=\sum_{i=1}^{10} x_{i} / 10$ is average GDP and $g_{i, t}=x_{i, t} / \sum_{i=1}^{10} x_{i}$ is GDP share for region $i$. If all Siberian regions have equal GDP, the Theil index takes the 
minimum value of zero, which implies complete equality. If regional GDP is equal to Siberian's GDP, the Theil index takes the maximum value of $\ln 10 \approx 2.30$, and value of $\ln 3977 \approx 8.29$ for if municipal GDP is equal to Siberian's GDP which implies complete inequality (to calculate the municipal-level Theil index, the sample size by the number of municipalities in the Siberia amounted to 3977 units). An advantage of the Theil index is its decomposability. Each municipal's contribution to macroregional economic disparities is given by $g_{i, t} \ln \left(10 g_{i, t}\right)$. To estimate spatial effect in our analyses on distribution the base-line specification is as follow:

$$
\begin{aligned}
& \ln Y_{i}=a_{0}+a_{1} \ln \operatorname{pod}_{i}+a_{2} \ln \operatorname{pod}_{i}^{2}+a_{3} \ln p o l_{i}+a_{4} \ln t r d+a_{5} \ln t t d+ \\
& +a_{6} \ln t r c+a_{7} \ln f m s_{i}+a_{8} s b b+a_{9} t s b+a_{10} \mathbf{x}+\varepsilon
\end{aligned}
$$

where $Y_{i}$ is measure of GDP; $\operatorname{pod}_{i}$ is population density; $\operatorname{pol}_{i}$ is measure of predicted local potential; $t r d_{i}$ is retail and wholesale trade; $t t d_{i}$ is exports and imports; $t r c_{i}$ is trucking; $f m s_{i}$ is firm size; $s b b_{i}$ is spatial boundary between regions; $t s b_{i}$ is spatial transboundary; $\mathbf{x}$ stands for vector of explanatory independent variables that control for additional predictors that are assumed to have an influence on $\ln Y_{i}$; and $\varepsilon$ is a heteroscedastic error. Geospatial data for this specification is defined in the geographic information system by ArcGIS. In this study local market potential as relative notions of space put forward by Garretsen et al. [6] calculate due to the difference in geographic distance during the interaction between the urban-ecosystems:

$$
\mathrm{pol}=\left(\sum \mathrm{pol}_{q}\right)\left(1+\frac{\sum p_{\mathrm{k}}}{100}\right)
$$

where $\mathrm{pol}_{q}$ is quantitative indicators of state statistical monitoring: labour, output, resource and investment local potential; pol $_{k}$ is qualitative indicators of state statistical monitoring: infrastructure, innovation and environmental local potential, $p o l_{k}=\sqrt[K]{\prod_{k=1}^{K} p o l_{k}}$ and $K$ is amount of indicators of state statistical monitoring of, e.g., dynamic indices of infrastructure development. The important features of the above model are presented below.

Is there any economic spillover from spatial concentration of economic activity, and if so, how does this spread to local emerging-economies markets? Is there any additional effect? Evaluating spillover effects of concentration and divergent across economies that are already linked through trade and interactions of economic agents is difficult because spatial connectivity often coincides with other significant regional events and factors of New Economic Geography (NEG) that could impact the real economy. In this paper, we overcome this problem by tracing spillovers via local housing markets. The importance of the effect of local housing markets has serious socio-economic implications for the macroregion. They are naturally different from the conclusions that can be drawn for industries. Factors determining the productivity of housing construction could contribute to damping the cycle in spatial distribution of economic activity. These tools are less applicable in the agricultural areas of Siberia. Thus, the difference in the impact on GDP in urban and rural areas should lead to very different approaches.

The summary statistics presented in Table 1 that gives brief description of the full sample in terms of scale and location of Siberian economy. Dataset is characterized by a high degree of heterogeneity, which can be explained as follows. Under the influence of resource endowment, regional uneven development strategy, and low population density, there are obvious interregional differences in Siberia, resulting in local markets being 
concentrated in regional central cities, causing a situation of oversupply in certain areas. At the same time, the demand for local markets in Siberian regions is often not met, which hampers the socio-economic development of the regions.

Table 1. Extensive Summary Statistics*.

\begin{tabular}{|c|c|c|c|c|c|}
\hline Variable & Observations & $\begin{array}{c}\text { Mean } \\
\text { value }\end{array}$ & $\begin{array}{c}\text { Std. } \\
\text { Dev. }\end{array}$ & min & max \\
\hline Population density & 3977 & 0.214 & 0.173 & 0.004 & 0.505 \\
\hline Local potential & 3645 & 1.111 & 1.127 & -0.815 & 3.803 \\
\hline Trade (retail and wholesale trade) & 3977 & 12.455 & 1.347 & 9.456 & 14.415 \\
\hline Total trade (exports and imports) & 3977 & 6.938 & 1.881 & 1.974 & 9.583 \\
\hline Trucking & 3977 & 6.831 & 1.053 & 4.094 & 8.399 \\
\hline Firm size & 3528 & 2.926 & 0.329 & 2.105 & 3.437 \\
\hline Spatial boundary between regions & 3977 & 0.72 & - & - & - \\
\hline Spatial transboundary & 3977 & 0.27 & - & - & - \\
\hline Housing prices & 3645 & 38287,500 & 8587,040 & 16420 & 56371 \\
\hline Housing construction & 3645 & 663,841 & 503,465 & 17 & 2588 \\
\hline
\end{tabular}

Note: * Source - Author's calculations based on data from Federal State Statistics Service.

It is also worth mentioning that population density, predicted local potential, trade, trucking, firm size (i.e., number of employees in thousands), age, capital intensity and average wage are expressed in natural logs. Spatial transboundary and boundary between regions are two dummy variables that were been include our specification to control for location. These variables take the value of one when regions are located as a neighbourhood with another federal district or inside of the whole sample (their mean is the percentage of observations); and 0 otherwise. The choice of this set of explanatory variables does not follow from the theoretical construction, but represents the authors' ideas about their significance for analysing the effect on heterogeneity. The sample period is spanned from 2005 to 2018. The full sample includes 10 regions for which there is a complete set of information about the empirical variables. Source: Russian Statistic Yearbook 2005-2018.

\section{Results and discussion}

The obtained regression results from estimating base-line specification for GDP expressed in natural log and measured in Theil index are presented in Table 2. Here we summarize the estimation results of the regression coefficients. First, consider regressions in which the left-hand side includes only $\ln Y_{i}=\ln g d p_{i}$ (the results are presented in columns 2.1-2.3, where dependent variable denote, respectively, the natural log of GDP per capita within region, mining sector and agriculture sector).

The first stage yields the following results. Population density and predicted local potential has a negative significant effect on labour productivity in region (especially for agriculture sector). The estimated parameters of spatial affect to agro-industrial sector within regions show the monitoring indicator at population density per unit area of 5154 
people (exponent of 0.359/2/0.021) in our proposed model. Hence, decreasing density which means decline of local markets economic scale of the regions is responsible for increasing average growth rate of GDP per capita in all Siberian regions of the sample investigated period. We interpret this as a sign that regional sector output is focused on consumption in local markets within the regions. The influence of control and additional explanatory variables in the second stage of the 2SLS regressions confirms this hypothesis statistically significant (Table 2, Panel A, Column 2.3, Rows 6, 7, 9, and 10).

Table 2. The impact of regressors on spatial distribution of economic activity: the second stage of the 2SLS regressions*.

\begin{tabular}{|c|c|c|c|c|c|c|}
\hline Regressors & (2.1) & (2.2) & (2.3) & (2.4) & (2.5) & $(2.6)$ \\
\hline \multicolumn{7}{|c|}{ Panel A: Differences in outcomes across sectors } \\
\hline Population density & $\begin{array}{l}-0.568^{*} \\
{[0.411]}\end{array}$ & $\begin{array}{l}0.700^{*} \\
{[2.491]}\end{array}$ & $\begin{array}{c}-0.359 * \\
{[0.756]}\end{array}$ & $\begin{array}{l}0.039 * \\
{[0.239]}\end{array}$ & $\begin{array}{l}1.503^{*} \\
{[2.541]}\end{array}$ & $\begin{array}{l}1.159^{*} \\
{[2.101]}\end{array}$ \\
\hline $\begin{array}{l}\text { (Population } \\
\text { density) }\end{array}$ & $\begin{array}{c}-0.065^{* * *} \\
{[0.022]}\end{array}$ & $\begin{array}{c}-0.039 * * \\
{[0.138]}\end{array}$ & $\begin{array}{l}-0.021^{*} \\
{[0.042]}\end{array}$ & $\begin{array}{c}-0.018 * * * \\
{[0.013]}\end{array}$ & $\begin{array}{c}-0.084 * * \\
{[0.141]}\end{array}$ & $\begin{array}{l}-0.064 * \\
{[0.017]}\end{array}$ \\
\hline $\begin{array}{l}\text { Predicted local } \\
\text { potential }\end{array}$ & \begin{tabular}{|l|}
$-0.297^{*}$ \\
{$[0.456]$}
\end{tabular} & $\begin{array}{l}1.221^{*} \\
{[2.759]}\end{array}$ & $\begin{array}{l}-0.533^{*} \\
{[0.838]}\end{array}$ & \begin{tabular}{|c|}
$0.094^{*}$ \\
{$[0.265]$} \\
\end{tabular} & $\begin{array}{l}1.968^{*} \\
{[2.814]}\end{array}$ & $\begin{array}{l}0.007^{*} \\
{[0.226]}\end{array}$ \\
\hline $\begin{array}{l}\text { Trade (retail and } \\
\text { wholesale trade) }\end{array}$ & $\begin{array}{l}0.414^{*} \\
{[0,709]}\end{array}$ & $\begin{array}{l}-4.735^{*} \\
{[4.296]}\end{array}$ & $\begin{array}{c}0.661^{*} \\
{[1.304]}\end{array}$ & $\begin{array}{l}-0.001^{*} \\
{[0.411]}\end{array}$ & $\begin{array}{l}-4.168 * \\
{[4.381]}\end{array}$ & $\begin{array}{l}0.219^{*} \\
{[0.353]}\end{array}$ \\
\hline $\begin{array}{l}\text { Total trade (exports } \\
\text { and imports) }\end{array}$ & $\begin{array}{l}-0.175^{*} \\
{[0,437]}\end{array}$ & $\begin{array}{l}2.666^{*} \\
{[2.648]}\end{array}$ & $\begin{array}{c}0.077^{*} \\
{[0,804]}\end{array}$ & $\begin{array}{l}0.110^{*} \\
{[0.254]}\end{array}$ & $\begin{array}{l}2.703^{*} \\
{[2.701]}\end{array}$ & $\begin{array}{l}-0.071^{*} \\
{[0.217]}\end{array}$ \\
\hline Trucking & $\begin{array}{l}0.425^{*} \\
{[0.372]}\end{array}$ & $\begin{array}{l}1.749^{*} \\
{[2.254]}\end{array}$ & $\begin{array}{c}0.531^{*} \\
{[0.684]}\end{array}$ & $\begin{array}{l}-0.110^{*} \\
{[0.216]}\end{array}$ & $\begin{array}{l}1.485^{*} \\
{[2.299]}\end{array}$ & $\begin{array}{l}-0.052 * \\
{[0.185]}\end{array}$ \\
\hline Firm size & $\begin{array}{l}0.010^{*} \\
{[1.023]}\end{array}$ & $\begin{array}{l}-4.481 * \\
{[6.201]}\end{array}$ & $\begin{array}{c}0.069 * \\
{[1.883]}\end{array}$ & $\begin{array}{l}-0.288^{*} \\
{[0.595]}\end{array}$ & $\begin{array}{l}-3.869 * \\
{[6.324]}\end{array}$ & $\begin{array}{l}0.191^{*} \\
{[0.509]}\end{array}$ \\
\hline $\begin{array}{l}\text { Spatial boundary } \\
\text { between regions }\end{array}$ & $\begin{array}{l}-0.950 * \\
{[1.128]}\end{array}$ & $\begin{array}{l}-0.346^{*} \\
{[6.831]}\end{array}$ & $\begin{array}{l}0.041^{*} \\
{[2.074]}\end{array}$ & $\begin{array}{l}0.194^{*} \\
{[0.655]}\end{array}$ & $\begin{array}{l}-0.079^{*} \\
{[6.966]}\end{array}$ & $\begin{array}{l}0.191^{*} \\
{[0.561]}\end{array}$ \\
\hline $\begin{array}{c}\text { Spatial } \\
\text { transboundary }\end{array}$ & $\begin{array}{l}-0.090^{*} \\
{[0.463]}\end{array}$ & $\begin{array}{l}0.504^{*} \\
{[2.804]}\end{array}$ & $\begin{array}{l}0.471^{*} \\
{[0.851]} \\
\end{array}$ & $\begin{array}{l}-0.121^{*} \\
{[0.269]}\end{array}$ & $\begin{array}{l}0.396^{*} \\
{[2.861]} \\
\end{array}$ & $\begin{array}{l}-0.097^{*} \\
{[0.230]} \\
\end{array}$ \\
\hline F-stat (het) & $3.731^{* *}$ & $1.669 *$ & $3.801 *$ & $2.523 *$ & $8.689 * * *$ & $1.639 *$ \\
\hline F-stat (hom) & $1.935^{*}$ & $1.470^{*}$ & $3.672^{* *}$ & $1.686^{*}$ & $3.124^{* *}$ & $1.484^{*}$ \\
\hline Adjusted R-squared & 0.304 & 0.084 & 0.667 & 0.261 & 0.567 & 0.225 \\
\hline \multicolumn{7}{|c|}{ Panel B: Differences in outcomes across spillovers } \\
\hline Housing prices & $\begin{array}{l}5,436 * * \\
{[0,342]}\end{array}$ & $\begin{array}{c}0,052^{*} \\
{[0,015]} \\
\end{array}$ & $\begin{array}{c}0,022^{*} \\
{[0,011]}\end{array}$ & $\begin{array}{c}3,429 * * * \\
{[0,631]} \\
\end{array}$ & $\begin{array}{c}0,043^{*} \\
{[0,014]}\end{array}$ & $\begin{array}{c}0,026^{*} \\
{[0,011]}\end{array}$ \\
\hline $\begin{array}{c}\text { Housing } \\
\text { construction }\end{array}$ & $\begin{array}{c}0,428^{*} \\
{[0,871]}\end{array}$ & $\begin{array}{c}0,018^{*} \\
{[0,011]}\end{array}$ & $\begin{array}{c}0,031^{*} \\
{[0,015]}\end{array}$ & $\begin{array}{c}0,365 * * \\
{[0,143]} \\
\end{array}$ & $\begin{array}{c}0,025^{*} \\
{[0,010]} \\
\end{array}$ & $\begin{array}{c}0,032 * \\
{[0,015]}\end{array}$ \\
\hline Adjusted R-squared & 0.083 & 0.041 & 0.068 & 0.081 & 0.021 & 0.039 \\
\hline Observations & 3977 & 3977 & 3977 & 3977 & 3977 & 3977 \\
\hline
\end{tabular}

Note: * The dependent variable is Theil index measure (columns 2.4-2.6), and is expressed in natural logs (columns 2.5 and 2.6). Robust standard errors adjusted for heteroscedasticity in brackets. *, **, and $* * *$ indicate significance at the $0.1,0.05$, and 0.01 levels, respectively. „F-stat (het)” reports Fstatistics for the excluded instrument from the first stage under the assumption of heteroscedasticity; and „F-stat (hom)” - under the assumption of homoscedasticity. 
In the next step, columns 2.4-2.6 illustrated influence the same regressors; in order to exclude endogeneity, for second stage of the 2SLS regressions, testing tools were introduced as a dynamic index for the same indicators in retrospect: the international trade showed a positive correlation, bigger addiction, compared with domestic trade, that means influence interaction of firms in local markets than a population distribution, what means confirmation of the NEG hypothesis about the role of local markets in the spatial development within regions. Firm size and retail and wholesale trade has a negative significant effect on spatial distribution of output in mining and positive of agriculture local markets. Most of these control variables have significant coefficients. The only notable difference between the results with and without these control variables is in the F-statistics for the excluded instrument from the first stage, they do drop once each of these control variables is included. Nonetheless, for the measure of spatial distribution, they still remain sufficiently strong not to worry about weakness of the instrument.

The estimated parameters of spatial distribution effect within regions show, sustainable local emerging-markets economic growth of these regions has positive spatial consequences for primary sector. Especially for agroindustry that it has a positive direct effect, and its elasticity coefficient shows that $1 \%$ increasing population density in natural logarithm may increase 1.159 \% spatial concentration of economic activity as Theil index measure in our proposed model. It means that increasing economic growth within local markets have negative spatial consequences for regional connectivity. In the agro-industrial sector of the Siberian macroregion, the increase in concentration degree of non-urbanized areas is greater by 2.9 percentage points and amounts to $4.1 \%$, while in urban-ecosystems areas the quantitative increase in the degree of concentration was $1.2 \%$ over the past three years. It all shows that with the current established technological chains for creating added value and the level of technological development, further growth of macroregional local markets is impossible without intensification in the agro-industrial sector, which would lead to domestic demand-based GDP growth, that is confirmation hypothesis about the decisive importance of local potential for development degree of both GDP per capita and a decrease spatial concentration in agriculture, which means that an increase in scale is associated primarily with an increase in labor productivity in an extensive aspect (Table 2, Panel A, Columns 2.4-2.6, Row 4).

Also results suggest that firm size and domestic trade in mining industry exerts a negative impact on labour productivity but its impact in agriculture firm is positive. This appears to signal the influence of economies of scale in Siberian agriculture sector, but the absent for mining sector: a negative and significant effect on both productivity and spatial distribution (these results are similar for the whole sample and for mining industry sample). The results suggest that a one-standard-deviation enlarging smaller firms in agro industrial sector in the same region, i.e. an increase of 32 percentage points in the firm size, is associated with a rise 6.3 per cent point in the localization of economic activity in the same sector (Table 2, Panel A, Column 2.6, Row 6).

Labor-migration flows in macroregions with low population density and large-scale distances between industrial centers are weakened by weak housing market activity. In order to estimate the degree of spatial factors' influence, we distinguished panel $\mathrm{B}$ of Table 2. We used the results of the identified effects as quasi-experimental parameters of the spillovers estimation model. Panel B of Table 2 reports the results. Thus our experimental assessment has shown evidence of strong spillovers in Siberia in the effects of shifting economic activity on the level of housing prices, which is a strong factor in the prices of local housing markets. The possibility of a decrease in effective demand is offset by a positive trend in the dynamics of price increases for housing, both on the primary and secondary housing market. 
The contribution of the primary sector of the macroregion in the dynamics of intraregional spatial distribution is ambiguous. With positive dynamics of the level of spatial concentration in non-urbanized areas, the agro-industrial sector positively correlates with the level of economic activity in this sector. The extractive industry has the opposite effect, which consists in the fact that with negative Theil index dynamics, there is a negative relationship between the growth of gross domestic regional product and the size of local markets for goods and resources. Further analysis shows that the greatest potential for the growth of macroregional connectivity will have the degree of spatial distribution of economic activity of the agricultural sector, due to such factors as the development of trade and interactions of economic agents. The influence of such factors as firm size and population density indicate the consolidation of industrial enterprises. Small farmers are leaving Siberian borders, and agro-industrial holdings are taking their place. In this case, it turns out that the size of the local market decreases, while in fact the gross domestic regional product grows both in absolute terms and as a measure of spatial distribution. This agrees with the results of other studies, which show an increase in the importance of other factors that we considered earlier.

As a result of our calculations, we obtained the following significant results, which are consistent with earlier research on this and related topics. The cross-disciplinary results can be described as follows. The two different primary sector industries in the macroregion have different trends in increasing economic activity and business activity. Increases in mining productivity characterize more effective increases in economies of scale, while increases in agricultural output are primarily associated with increases in scale. Thus, there is a decrease in the rate of cost reduction (labor, transportation and capital) compared to the production of building materials, where the area of occurrence of the ore body, which determines the amount of mineral reserves, is the determining factor. It should also be noted that, consistent with the findings, in the example Siberian macroregion, the mining industry is dominated by large-scale corporations, while in agriculture it is customary to consider small forms of management as the most efficient. Consequently, the dynamics of cost reduction of agro-holdings will always be less than that of mining enterprises and corporations, so the essence of government support for agricultural development is more inclined to support farmers and small businesses.

The difference in cost increases compared to economic activity scale growth in the spatial aspect leads us to the conclusion that the most effective functional transformation is needed in agriculture, where it will get more tangible results with a greater probability and efficiency degree. Industry 4.0 technologies allow more profitable results from the digital transformation of the main technological value chains, which can level the effect compared to mining enterprises in the form of reduced differences in the rate of increase in costs and profitability. To date, the most promising information resources used in agriculture are the following tools and software products:

- spatial digital technologies in the agricultural sector systematizing information and promoting integration with the cadastral information system, which improves the efficiency of public expenditures to subsidize the costs of agricultural crop production;

- data collection based on telemetry systems;

- satellite imagery and fixed environmental emission recording tools that can indicate economic development degree in emerging markets;

- digital markers for ecological-geographical mapping and monitoring of soil conditions during the application and distribution of chemical agents (precision farming);

- Global Navigation Satellite System digital data transmission facilities for geophysical navigation messages for operational monitoring as part of navigation of automated equipment, machinery and mechanisms integrated into the cyber-physical system. 
All of the above components can be not only a provider, but also a cloud storage of large-scale data for monitoring the socio-economic development of regional systems at any levels in order to determine localization areas of socio-economic phenomena, which are factors in measuring the degree of area dispersion, clustering and connectivity.

In showing that Siberian local markets draw their ownership advantages from the infrastructural environment, we demonstrate that macroregion emerging markets offer an important context to explore the impact of spillovers on spatial distribution of economic activities. This explains why an infrastructural perspective is instrumental to better conceptualize and understand the impact of government policy on long-term strategy of economic development.

\section{Conclusions}

By integrating two different, but complementary, theoretical approaches, our framework considers the role that municipaly level factors play in explaining determinants of regional agroindustry and spillovers between macroregion local markets. The analysis of a largescale dataset enables us to distinguish among the impacts of these regressors and to provide evidence on the relative contribution and to monitor effectiveness of these determinants in spatial spillovers. Taking into account the development trends in agricultural and industrial zones development, it is possible to build situational scenario for macroregional economic modern solutions-based growth that technologies of Industrial 4.0 suggest to raise values from digital transformation. The above methodology, tested in Siberian conditions, is suitable for use in the monitoring system both on a regional scale and on municipal level to identify differences and compare industries growth dynamics and the development of regions, since the level of uneven spatial activity of market entities between regions is greater than within one local market. The use of NEG hypotheses as a theoretical basis in the proposed monitoring system allows taking into account infrastructural and resource potentials for increasing the functionality and predictability of monitoring results which is important for investors and government in management.

The results of our research can help representative authorities in the process of designing effective methods of managing local markets for products and resources. Also confirmed by other studies, our results will encourage the search for new directions in the study of the formation and functioning of local markets within the framework of spatial analysis. In addition, our experimental evaluation has shown evidence of strong spillovers in Siberia in the effects of shifting economic activity on the level of housing prices, which is a strong factor in the prices of local housing markets.

Authors grateful to anonymous referees and researchers of Kuban State Agrarian University named after I.T. Trubilin for helpful comments.

\section{References}

1. M. Fujita, P. Krugman, T. Mori, European Economic Review. 43 (1999).

2. G. Hanson, Journal of International Economics. 67 (2005).

3. P. Picard, D.-Z. Zeng, Journal of Development Economics. 77 (2005).

4. J. G. Williamson, Economic Development and Cultural Change. 13 (1965)

5. H. Theil, Economics and information theory (Amsterdam: North Holland, 1967).

6. H. Garretsen, R. Martin, Spatial Economic Analysis. 5 (2010). 